\title{
The Description of Family Quality of Life in Parents with Empty-Nest Syndrome
}

\author{
Viovenica Bongyoga ${ }^{1}$ Widya Risnawaty ${ }^{1 *}$ \\ ${ }^{1}$ Faculty of Psychology, Universitas Tarumanagara, West Jakarta, Jakarta 11440, Indonesia \\ "Corresponding author. Email: widyar@fpsi.untar.ac.id
}

\begin{abstract}
The goal of this study is to obtain the description of family quality of life in parents with empty-nest syndrome. Empty-nest syndrome is a common phenomenon which occurs when child is grown up and decides to be live separately with the parent. The phenomenon takes place when child is entering the early adulthood phase and faced with various experiences which commonly occurs as an adult. Generally, an adult has the opportunity to get higher education in college, or to focus on their jobs and career, or to choose marriage with their romantic partner. When these things happen, parents who get used on raising and nurturing their child for years have the possibility on being 'empty' after child's departure. This existing phenomenon calls to be studied to see the family quality of life with a couple of parents who experiences the empty-nest syndrome as the analysis unit. This study was studied using a phenomenological qualitative approach to explore the subjective understanding of parents in dealing with this phenomenon. Participants in this study were three pairs of parents who are in the middle adult development phase and live separately from their children because the children are married/working/studying. The interview process lasted for one month (November December 2020). Data were obtained through interviews as a form of screening for signs of empty-nest syndrome experienced by subjects, then continued with interviews related to dimensions of family quality of life. The results showed that the subject's empty-nest syndrome affects the dimensions of the quality of family life, especially emotional well-being, which is marked by the subject's feelings of sadness 1-3 months after the child's departure. Other dimensions such as family interaction, parenting, and physical/material well-being also change in each subject.
\end{abstract}

\section{Keywords: family quality of life, empty nest syndrome, middle adulthood, early adulthood, family}

\section{INTRODUCTION}

Family is the first place for human to grow their physical, cognitive, and socioemotional development; consists of two or more member who's bounded in blood, marriage, or adoption [1][2]. Process of development is a life-time process and every phase of it involves new goals to be achieved [3][2]. Both parents and children will deal with their developmental task, such as parents with their peaked parenting phase and children when they're entering the early adulthood phase [2][4]. Children are facing maturity process where they become independent with adulthood tasks, such as finishing education, starting a new career, and long-term relationship with romantic partner in marriage [5][6]. Children's independence marked as their departure from parents' house to accomplish their responsibility as an early adult [7].

This phenomenon is generally known as empty nest syndrome, where grown up children separate their residence with parents and feelings such as stress, sadness, sense of loss, emotional distress, and frustration, and anxiety that leads to identity crisis dan marital conflict [8][7][9][10][2]. Although this condition is not a clinical diagnosis, however, parents may have a hard time, especially the ones that are actively involved in children's nurture and development [2].

There are parents who take this experience as a dark time that makes them sad, lonely, and isolated, yet others take this transition as a normal phase that needs to be happen, because this is a part of maturity process for children to become independent. The departure of a child can also be a moment for parents and children to be able to improve direct communication patterns that generally experience hostility, so that the child's departure does not always lead to negative changes [23]. These different perspectives occur because of the uniqueness from each family that differ them from other families, even every member of it also has the characteristics that differ them from any other member [11][4].

If this is studied by the dimensions of family quality of life by [12], this empty nest transition affects family condition such as family interaction, parenting, emotional well- 
being, and physical/material well-being. Parents need to understand, accept, and adapt to be able to get through this transition [13].

Seeing the phenomenon above, a question arises: how is the family quality of life descripted in parents who experience empty nest syndrome? The different responses encourage a further study towards the description of family quality of life in parents with empty nest syndrome. This study is conducted with qualitative phenomenological approach to dig a deeper subjective meaning from participant with empty nest syndrome. The last study of family quality of life and empty-nest syndrome are taken into consideration, because there was a limited study of these phenomenon. The last study of family quality of life doesn't involve family with grown up children. This adds up consideration to conduct this study.

\section{BACKGROUND}

Empty-nest syndrome is a transitional period that occurs when children live independently and live separately from their parents, followed by feelings of sadness, loss, and loneliness felt by the parents who are left behind [19] [10][20]. [21] describes the term empty-nest syndrome as "a symbol of a collection of symptoms that are present in dealing with feelings of loss when a child grows up and leaves the house". [22] defines empty-nest syndrome as an experience that causes a crisis of identity and a sense of loss in parents after the child leaves home and lives apart from the parents. The phenomenon of empty-nest syndrome is classified into three transitions, namely when all children still live with their parents, when one child leaves and lives separately from the child, until when all children live separately from their parents [23].

Empty-nest syndrome is a condition that parents generally experience when facing the departure of their adult children [21]. These changes can have the effect of changing the emotional condition of the parents who are left behind. Here are some of the signs shown by parents when experiencing empty-nest syndrome [24][8][25][23].

\section{METHODS}

This study takes a couple of parents as participant. There are some certain characteristics of parents who: (a) is currently in a middle adulthood development (40 to 65 years old); (b) domiciled in Jakarta, Bogor, Depok, Tangerang, or Bekasi; (c) is married; (d) live separately with their children who is married or working or in college and in a early adulthood development (20 to 40 years old); (e) is experiencing signs of empty-nest syndrome such as loneliness, isolated, identity crisis, and long-term sadness $[24][8][25][23]$ during the first 1-6 months after child's departure.

The total amount of participant in this study is three couples of parents. Participants are being involved in an in-depth interview that is differed as two steps; preinterview as an empty-nest syndrome screening, followed by a family quality of life interview with parents who experienced empty nest syndrome. Researcher composes the interview guidelines based on the concept of family quality of life dimension, constructed by [12][26]. The total interview amount is two times, each took 30-90 minutes.

Analysis data technique is done by composing the verbatim transcript for each participant, continued with the coding steps to categorize each theme from the interview results. The steps are continued with the construction of tabbed themes for each interview steps. After the interview data are written down, the next step is analysing interview data based on empty-nest syndrome and family quality of life theory.

\section{FINDINGS AND DISCUSSIONS}

Three couples of parents have shown the signs of emptynest syndrome they experienced aster child's departure due to marriage, career, and education. This marked off as the loneliness and sadness that felt by subjects during the first 1-3 months of child's departure. Every subject has experienced loneliness due to less direct interaction and the daily bustle that makes them hard to meet face-to-face directly. Sadness is marked off as the intensity of subject crying through the first months after child's departure. Subjects are repetitively telling their desire to live together with child, but children have their own personal activity that makes them live separately with parents. Parents often feel the absence of their grown-up children and have the urge to adapt with the situation. Subject 1 be open with her spouse about the hard feeling she gets when she overthinks about her children's condition. Parents have hard time when they get no chance to directly meet with their children during big/celebrative day. Based on the result of interviews, all subjects have shown reduction on one dimension of family quality of life: emotional well-being. A change in family conditions after the child's departure caused adjustments that subject 1 needed to make. The adjustment process that takes place does not necessarily run smoothly.

Subject 1 took a month to get used to the absence of children at home. The two subjects also experienced differences in terms of adjusting to the child's departure, due to differences in the intensity of the parenting role of subject 1 . Based on the signs of empty-nest syndrome, the same feelings of sadness and loneliness were experienced by subject 1 .

Subject 2 both experienced feelings of sadness and loneliness. Changes in the role of parents were also experienced by the two subjects, where the role that the subject can do as parents of a child who has lived separately and independently is to provide reminders and advice to the child.

Subject 3 experienced feelings of sadness, loss, and loneliness in facing the departure of their children. This 
feeling arises in the first one to three months after the child's departure, because parents who are not used to the departure of the previous child always live with the subject. However, both subjects were able to overcome this uncomfortable feeling one to three months after the child's departure, by maintaining good distant communication with the child.

Based on the results of interviews with the three pairs of parents, it was seen that there were differences in the responses given by the subjects. This can arise because each family has its own characteristics that differentiate one family from another [11]. This is due to differences in the background of each pair of subjects, such as work, daily activities, the role of the subject as parents, the number of family members who live separately, and the reasons for the separation of the subject from the child. Each subject interpreted his attitude and feelings towards the child's departure in their own way.

Each subject interpreted feelings of loneliness, loss of identity, feelings of isolation, and sadness differently. Each pair of parents also interpret the quality of life for their respective families in various ways. This is due to differences in understanding of the empty-nest syndrome phenomenon experienced by each subject. This difference arises from various subject backgrounds, ranging from the type of work, the reasons for the separation of the child from the parents, the daily activities of each subject, and the number of members who still live with the subject.

The first pair of parents felt a disturbance in the dimensions of family interaction, parenting, and emotional well-being after the child's departure. This is due to the subject's adjustment process when the first month the child's departure feels heavy. Subjects try to calm each other down when feelings of sadness, worry, or loneliness for the child arise. Not infrequently, the subject continues to convey his desire to be able to gather directly and spend time with the children, but the subject tries to suppress these feelings because the subject realizes that the child already has the responsibility and his own life. The subject also tries to be able to adjust his role as mother to children who are independent and mature. Initially, the change in the subject's role in caring for children was disturbed, because of the subject's inability to manage children's daily needs. The subject tries to understand that the child is independent and is able to meet their personal needs, but concerns arise if the child is unable to prepare their needs. The subject also tries to overcome the uncomfortable feelings that arise when facing the departure of a child by telling stories with a partner, so that he feels comforted and calm when feelings that bother him arise. Even though the subject experienced a tough period, in the first month of the child's departure, the subject still tried to process and adapt himself.

The second pair of parents experienced changes in the dimensions of family interaction, parenting, emotional well-being, and physical / material well-being. The subject explained the changes in communication between parents and children which reduced the duration of communication. Even though the subject said that long distance communication with children was smooth, he still conveyed his desire to be together with children. The subject also conveyed his difficulty in chatting freely over the phone, because the subject felt more comfortable when chatting in person. The subject also conveyed that he always surrendered to God when he felt uncomfortable feelings towards children. However, the subjects felt that the limitations in communicating made clashing with children reduced, because the frequency of chatting was reduced compared to before the children lived apart. The subject also experienced changes in terms of educating children. The subject explained that the child's departure to Japan is a form of subject education so that the child becomes independent and can take responsibility for his life. The subject explains his happy feelings when the child asks him for suggestions, so that the subject does not feel disturbed when the childcare process can no longer be done directly by the subject, but through suggestions, input, or advice in order to help the subject consider something. The subject also conveyed the severe conditions experienced at the beginning of the child's departure. The subject described the process of letting the child go by praying and convincing himself that the child was able to take care of himself while in Japan. Subjects often cried in the first month after the child left. But in the end the subject can convince himself and try to let go by praying to God. One month passed, the subject began to get used to the changes in his activities at home, namely starting to change the way the subject communicated with children via telephone. The child's departure to work also helps the subject to increase the cost of income for home needs, so that the child's departure can increase the physical / material dimension of the subject's well-being. In the subject of the third parent pair, the child's departure affects the dimensions of family interaction and emotional well-being on the subject. There is an effect of children's departure on the family interaction dimension, although it is not large. Subject communication with children that previously took place every day, and face-to-face, has now turned into online and indirect communication. This initially annoys the subject who is accustomed to greeting children directly. However, the subject did not feel disturbed and only needed to adjust to the child's departure. At the beginning of the child's departure, the subject also felt the loss of the child's figure who had always lived together with the subject. This feeling was felt by the subject at one month after departure.

Each subject interpreted feelings of loneliness, loss of identity, feelings of isolation, and sadness differently. Each pair of parents also interpret the quality of life for their respective families in various ways. This is due to differences in understanding of the empty-nest syndrome phenomenon experienced by each subject. This difference arises from various subject backgrounds, ranging from the type of work, the reasons for the separation of the child from the parents, the daily activities of each subject, and the number of members who still live with the subject.

The first pair of parents felt a disturbance in the dimensions of family interaction, parenting, and emotional well-being after the child's departure. This is due to the subject's adjustment process when the first month the 
child's departure feels heavy. Subjects try to calm each other down when feelings of sadness, worry, or loneliness for the child arise. Not infrequently, the subject continues to convey his desire to be able to gather directly and spend time with the children, but the subject tries to suppress these feelings because the subject realizes that the child already has the responsibility and his own life. The subject also tries to be able to adjust his role as mother to children who are independent and mature. Initially, the change in the subject's role in caring for children was disturbed, because of the subject's inability to manage children's daily needs. The subject tries to understand that the child is independent and is able to meet their personal needs, but concerns arise if the child is unable to prepare their needs. The subject also tries to overcome the uncomfortable feelings that arise when facing the departure of a child by telling stories with a partner, so that he feels comforted and calm when feelings that bother him arise. Even though the subject experienced a tough period, in the first month of the child's departure, the subject still tried to process and adapt himself.

The second pair of parents experienced changes in the dimensions of family interaction, parenting, emotional well-being, and physical / material well-being. The subject explained the changes in communication between parents and children which reduced the duration of communication. Even though the subject said that long distance communication with children was smooth, he still conveyed his desire to be together with children. The subject also conveyed his difficulty in chatting freely over the phone, because the subject felt more comfortable when chatting in person. The subject also conveyed that he always surrendered to God when he felt uncomfortable feelings towards children. However, the subjects felt that the limitations in communicating made clashing with children reduced, because the frequency of chatting was reduced compared to before the children lived apart. The subject also experienced changes in terms of educating children. The subject explained that the child's departure to Japan is a form of subject education so that the child becomes independent and can take responsibility for his life. The subject explains his happy feelings when the child asks him for suggestions, so that the subject does not feel disturbed when the childcare process can no longer be done directly by the subject, but through suggestions, input, or advice in order to help the subject consider something. The subject also conveyed the severe conditions experienced at the beginning of the child's departure. The subject described the process of letting the child go by praying and convincing himself that the child was able to take care of himself while in Japan. Subjects often cried in the first month after the child left. But in the end the subject can convince himself and try to let go by praying to God. One month passed, the subject began to get used to the changes in his activities at home, namely starting to change the way the subject communicated with children via telephone. The child's departure to work also helps the subject to increase the cost of income for home needs, so that the child's departure can increase the physical/material dimension of the subject's well-being.
In the subject of the third parent pair, the child's departure affects the dimensions of family interaction and emotional well-being on the subject. There is an effect of children's departure on the family interaction dimension, although it is not large. Subject communication with children that previously took place every day, and face-to-face, has now turned into online and indirect communication. This initially annoys the subject who is accustomed to greeting children directly. However, the subject did not feel disturbed and only needed to adjust to the child's departure. At the beginning of the child's departure, the subject also felt the loss of the child's figure who had always lived together with the subject. This feeling was felt by the subject one to three months after the child's departure. However, this feeling can be overcome by the presence of the children of other subjects.

During the research, there were limitations in terms of data collection (interviews) that were conducted online due to the COVID-19 pandemic, so that observations could not be carried out optimally such as direct interviews. During the interview, unexpected things can happen, such as signal interruptions that prevent online interviews from running optimally. Another limitation is also marked by the heterogeneity of the characteristics of each participant, such as the number of children who still live with their parents and socio-economic status, which also influence the results of this study.

\section{CONCLUSIONS}

Based on the data obtained from the entire series of interviews with the subject, it can be concluded that the first, second, and second parent pairs experience signs of empty nest syndrome. Each subject experienced the depth of markings differently. Each subject interpreted feelings of loneliness, loss of identity, feelings of isolation, and sadness differently. This difference arises from diverse subject backgrounds, for example work background, daily activities, reasons for separation from children, and the number of children each subject has.

After the child's departure, the three subjects experienced changes in the family interaction dimension. The three of them are faced with changes in the communication media that were previously carried out directly and are now changing through video or audio telephone.

The dimensions of parenting in the three subjects were also adjusted after living separately from children. The three subjects are no longer directly involved in the child's life because the child has grown up and lives independently. The involvement that parents give to children is in the form of providing input, advice, suggestions, and reminders for children. The education that the three subjects give to children is an effort for parents to let the child go to be able to live independently.

All three subjects showed changes in emotional well-being after living separately from children. All three have their own uniqueness in dealing with uncomfortable feelings arising from the departure of the child. Through their 
respective peculiarities, there is a common thread which indicates that the three subjects experience difficult emotional conditions when facing the departure of a child. As for the subject who cried when processing the child's departure, then the subject's great concern about the child's life without the subject, there was also an anxious attitude about the subject's condition that had no one in the city where he lived. There are three different ways regarding the empty-nest syndrome phenomenon experienced by parents, namely feelings of sadness when facing the departure of a child. The three pairs of subjects explained their sadness in the process of letting the child go. This process is often followed by a crying subject. The subject also repeatedly expressed his desire for children to be together. However, the subject finally understood the situation of his child who had a life of his own. This shows a change in the emotional well-being dimension of each subject.

The physical / material well-being dimension of each subject is not much affected by the child's departure. Each subject can still meet their needs for transportation, health services, and family expenses. Different things arise in the feeling of security at home which is caused by the number of family members who still live with the child. Thus, the different conditions of each family lead to a different understanding of the physical / material dimensions of well-being.

Based on the results of the entire series of interviews with the three pairs of subjects, an overview of the quality of family life for parents with empty-nest syndrome is obtained. The dynamics in each dimension will be presented in the discussion.

\section{REFERENCES}

[1] Health Resources \& Servies Administration. (2017, April). Definition of family. https://www.hrsa.gov/gethealth-care/affordable/hill-burton/family.html\#: :text= Previously\%20provided $\% 20$ in $\% 20$ guidelines*,as $\% 20 \mathrm{~m}$ embers\%20of\%20one\%20family.

[2] Papalia, D. E., \& Martorell, G. (2021). Experiencing Human Development. In McGraw-Hill Education (14th ed.). McGraw-Hill Education.

[3] Baltes, P. B. (1987). Theoretical Propositions of Life-Span Developmental Psychology: On the Dynamics Between Growth and Decline. Developmental Psychology, 23(5), 611-626. https://doi.org/10.1037/ 0012-1649.23.5.611

[4] Santrock, J. (2013). Life-Span Development (14th ed.). McGraw-Hill Education.

[5] Erikson, E. (1968). Identity and Youth Crisis. W. W. Norton.
[6] Seitzer, M. (2019, November 4). Adult children: The guide to parenting your grown kids. https://extramile.thehartford.com/family/parenting/ parenting-adult-children/

[7] Loose, D. (2018). The empty nest: What I learned during my daughter's first year away. https://www. washingtonpost.com/lifestyle/on-parenting/the-emptynest-what-i-learned-during-my-daughters-first-yearaway/2018/08/07/23d1832a-94fc-11e8-a679b09212fb69c2_story.html

[8] Chen, D., Yang, X., \& Aagard, S. D. (2012). The Empty Nest Syndrome: Ways to Enhance Quality of Life. Educational Gerontology, 38(8), 520-529. https:// doi.org/10.1080/03601277.2011.595285

[9] Morin, A. (2019, November 13). 5 signs and symptoms of empty nest syndrome. https://www. verywellfamily.com/signs-of-empty-nest-syndrome4163787

[10] Mayo Clinic Staff. (2020, April 14). Empty nest syndrome. https://www.mayoclinic.org/healthy-lifestyle /adult-health/in-depth/empty-nest-syndrome/art20047165

[11] Riggs, B. A., \& Tweedell, C. B. (2006). Marriage and family. In Triangle Publishing (2nd ed.). Triangle Publishing. https://doi.org/10.4324/9780203116739

[12] Zuna, N. I., Selig, J. P., Summers, J. A., \& Turnbull, A. P. (2009). Confirmatory factor analysis of a family quality of life scale for families of kindergarten children without disabilities. Journal of Early Intervention, 31(2), 111-125. https://doi.org/10.1177/ 1053815108330369

[13] Smith, S. (2020, Juli 29). How does your relationship with your parents change after marriage? https://www.marriage.com/blog/relationship/how-doesyour-relationship-with-your-parents-change-aftermarriage/

[14] Britannica. (1999). Family. https://www.britannica. com/topic/family-kinship

[15] Zuna, N., Summers, J. A., Turnbull, A. P., Hu, X., \& Xu, S. (2010). Theorizing About Family Quality of Life. https://doi.org/10.1007/978-90-481-9650-0_15

[16] Strong, B., Devault, C., \& Cohen, T. F. (2011). The Marriage and Family Experience Intimate Relationships in a Changing Society. In International Journal of Social Research Methodology (Vol. 7, Issue $1)$. 
http://www.tandfonline.com/doi/abs/10.1080/13645570 310001640653

[17] Titelman, P. (2013). Clinical Application of Bowen Family Systems Theory. Routledge.

[18] The Center for Family Systems Theory. (2020). History of family systems theory. www.family systemstheory.org/history/

[19] Psychology Today. (n.d.). Empty nest syndrome. https://www.psychologytoday.com/intl/conditions/empt y-nest-syndrome

[20] Preedy, V. R., \& Watson, R. R. (2010). EmptyNest Family. In Handbook of Disease Burdens and Quality of Life Measures. https://doi.org/10.1007/9780-387-78665-0_5581

[21] Oliver, R. (1977). The "empty nest syndrome" as a focus of depression: a cognitive treatment model, based on rational emotive therapy. Psychotherapy, 14(1), 8794. https://doi.org/10.1037/h0087497

[22] Rosen, E., Ackerman, L., \& Zosky, D. (2002). The sibling empty nest syndrome: The experience of sadness as siblings leave the family home. Journal of Human Behavior in the Social Environment, 6(1), 6580 .

[23] Mitchell, B. A., \& Lovegreen, L. D. (2009). The empty-nest syndrome in midlife families: A multimethod exploration of parental gender differences and cultural dynamics. Journal of Family Issues, 30(12), 1651-1670. https://doi.org/10.1177/0192513 X09339020

[24] Bouchard, G. (2013). How Do Parents React When Their Children Leave Home? An Integrative Review. Journal of Adult Development, 21(2), 69-79. https:// doi.org/10.1007/s10804-013-9180-8

[25] Davis, E. M., Kim, K., \& Fingerman, K. L. (2018). Is an Empty Nest Best? Coresidence with Adult Children and Parental Marital Quality before and after the Great Recession. Journals of Gerontology - Series B Psychological Sciences and Social Sciences, 73(3), 372-381. https://doi.org/10.1093/geronb/gbw022

[26] Risnawaty, W., Agustina, \& Suryadi, D. (2020). Psychometric Properties of Beach Center Family Quality of Life Scale for Indonesian Families' Children Without Disabilities. 1-7.

[27] Raup, J. \& Myers, J. E. (1989). The empty nest syndrome: Myth or reality? Journal of Counseling and Development, 68(2) 180-183. 